ISSN:1991-8178
EISSN: $2309-8414$

\title{
Prevalence of Trematode Larval Infections in Some Red Sea Snails
}

\author{
${ }^{1,2}$ Amaal Hassan, ${ }^{1}$ Muslimah Al-solami and ${ }^{1,3}$ Sabah M. Hassan \\ ${ }^{1}$ Biology Department, Science College, King Abdulaziz University, Jeddah, Saudi Arabia \\ ${ }^{2}$ Zoology Department, Faculty of Science, Sohag University, Sohag, Egypt. \\ ${ }^{3}$ Department of Genetics, Faculty of Agriculture, Ain Shams University, Cairo, Egypt.
}

Address For Correspondence:

Muslimah Alsolami Biology Department, Science College, King Abdulaziz University, Jeddah, Saudi Arabia.

Email: m-n-solima@ hotmail.com

A R T I CLE INF O

Article history:

Received 12 October 2017

Accepted 22 December 2017

Available online 31 December 2017

Keywords:

Marine snails, Prevalence, Trematode

larvae, Cercaria

\begin{abstract}
A B S T R A C T
Marine snails play an important role in the transmission of cercariae to fish as a source of zoonotic diseases. In Saudi Arabia, studies on parasitic infections in marine snails are rare. In the current study, a total of 550 marine snails belonging to the genus, Nerita were collected randomly from Obhor bay, Red Sea at Jeddah city, Saudi Arabia. Snails were collected monthly at the period from January to December 2016. They were exposed to light and crushed to assess the presence of larval trematodes. The most prevalent infected snail species was $N$. histrio (31.94\%). Nine distinguishable cercariae were identified; Haematoloechus similis, Virgulate, Microphalliae, Ascorhytis charadriformis, litorina saxatilis VII, litorina saxatilis V, Maritrema lingulla, Microphallus similis and Furcocercous cercariae. Virgulate cercaria was the most prevalent type of recorded cercariae $(33.89 \%)$. There is a positive correlation between infection prevalence and snails' length. Trematode infection of marine snails is influenced by temperature and varied seasonally. Such studies can assist in collecting data on the ecological relevance of disease distribution in the sympatric fish and the pattern of transmission of digenean trematodes by snails and finally, in prevention and control of the following fish and human diseases.
\end{abstract}

\section{INTRODUCTION}

Mollusks are important to humans as food, decoration and materials. Gastropods are one of the most diverse and largest group of mollusks, with more than 62,000 described living species and they comprise about $80 \%$ of living mollusks. Most snails can become intermediate hosts for trematode cercariae, which may be transmitted to humans and animals. The life cycle of trematodes is very complex, as they require an intermediate host such as snails or fish for the maturation to the infective stage. Sporocysts and redia are formed inside the first intermediate host and feeds through diffusion across the tegument and develop into cercariae inside the snail. The cercariae are adapted for dispersal outside the snail and exhibit a large variety in morphology to recognize and penetrate the second intermediate host. They have behavioral and physiological adaptations, which are not found in earlier stages. To determine the ability of a snail species or a snail population to act as an intermediate host of a given species of digenea, it is necessary to measure several parameters such as the prevalence and intensity of snail infection (Graczyk \& Fried 1999). Until present, only few studies have been carried out on the diversity and abundance of cercarial infection in the Red Sea snails. There is an urgent need to obtain information regarding environmental influences acting on emergence of cercariae in marine system (Koprivnikar \& Poulin 2009). Thus, the aim of the present study was to elucidate the monthly and seasonal changes in the rate of cercarial infections of marine Nerita snails, as well as the effect of snails' length and temperature on the infection prevalence in the Red Sea, Jeddah coast. Saudi Arabia.

Open Access Journal

Published BY AENSI Publication

(C) 2017AENSI Publisher All rights reserved

This work is licensed under the Creative Commons Attribution International License (CC BY).

http://creativecommons.org/licenses/by/4.0/

(c) (i) Open Access

To Cite This Article: Amaal Hassan, Muslimah Al-solami and Sabah M. Hassan Prevalence of Trmatode Larval Infections in Some Red Sea Snails Aust. J. Basic \& Appl. Sci., 11(16): 69-76, 2017 


\section{MATERIALS AND METHODS}

\section{Collection and Identification of snails:}

A total of 550 marine snails were collected randomly from Obhor bay, which located about $30 \mathrm{~km}$ north of Jeddah city on the east coast of the Red Sea, west of Saudi Arabia, with global positioning system (GPS) reading of $21^{\circ} 32^{\prime} 36 \mathrm{~N}$ and $39^{\circ} 10^{\prime} 22 \mathrm{E}$ (Figure 1). Snails were collected using a wooden handle paddle. They were put in glass jars containing fresh seawater and were transferred to the Parasitology laboratory, Department of Biology, Faculty of Science, King Abdul Aziz University, Jeddah. Snails were collected during the period from January to December 2016.

Collected snails were identified according to their shell morphology using identification keys as Rusmore-Villaume (2008) and Knaap \& Loker (1990). They were found belonging to the family Neritidae and the genus Nerita, which is classified into six species; Nerita albicilla, N. grayana, N. polita, N. quadricolor, N. orbignyana and N. histrio (Figure 2).



Fig. 1: Site of snails' collection from the Red Sea, Jeddah coast (by Google map)

\section{Measurement of shell length:}

Maximum shell length was measured from the apex to the end of the shell using a Vernier Calipers Series 530-Standard Model. Snails species were classified according to their length into five classes, 2-3.9mm, 45.9mm, 6-7.9mm,8-9.9mm,10-11.9mm and 12-14mm.

\section{Shedding and harvesting of cercariae:}

Shedding and harvesting of cercariae were done according to Aboelhadid et al. (2016). Different snail species were separated in plastic specimen cups, cleaned and each snail was put in petri dish containing seawater and were kept in the laboratory at $23^{\circ} \mathrm{C}$. They were exposed to artificial light for two hours. Water in each dish was checked at short intervals for emerging cercariae under a binocular dissecting microscope. The infected snails were separated and put in $250 \mathrm{ml}$ beaker to facilitate emerging of cercariae. The non-shedding snails were crushed and examined under the binocular dissecting microscope searching for early larval trematode stages. Living cercariae were stained with diluted vital stain, neutral red or methylene blue. The stained cercariae were examined and photographed under a research microscope. They were identified according to their morphological characters using taxonomic keys and recent articles.

\section{Statistical analysis:}

The data were analyzed using Chi-square analysis to compare the infection rate capacity between infected and non-infected snails. The differences in snail's species between non-infected and infected during all months and different lengths were tested separately. All statistical analyses were performed using SPSS software program (version 22). Probability of $\mathrm{P}<0.05$ was regarded as significant at $95 \%$ confidence limit. 

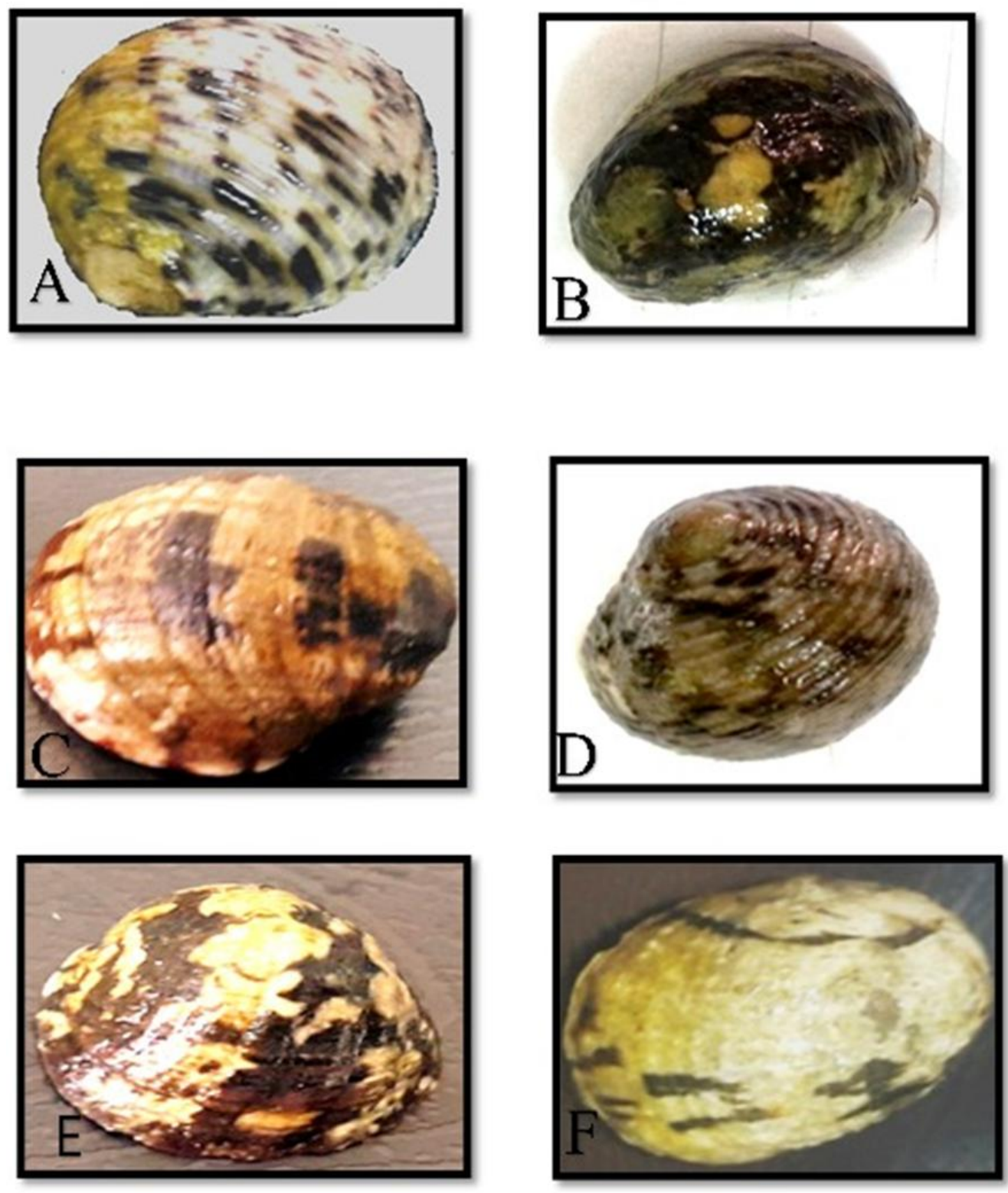

Fig. 2: The collected snails species of the genus Nerita, A- Nerita histrio, B-Nerita albicilla, C- Nerita orbignyana, D-Nerita quadricolor, E- Nerita grayana, F-Nerita polita

\section{Results:}

Overall prevalence of infection in snail's species:

A total of 550 marine snails were collected randomly from Obhor region at Jeddah coast. The snails were classified based on their shell morphology and were found belonging to family Neritidae and genus Nerita. Six species from the genus Nerita were identified and examined; (189 of Nerita albicilla, 91 of N. grayana, 53 of $N$. polita, 93 of $N$. quadricolor, 52 of $N$. orbignyana and 72 of $N$. histrio. Nerita albicilla was found to be infected with three types of cercariae (virgulate cercaria, maritrema lingulla and Litorina saxatilis V). Nerita grayana was found to be infected with two types of cercariae (litorina saxatilis V and litorina saxatilis VII). Furcocercus cercaria infects $N$. polita and cercaria of Maritrema lingulla infects N.quadricolor. Four types of cercariae were collected and investigated from N. orbignyana; Microphallus similis, Haematoloechus similis, Maritrema lingulla and Ascorhytis charadriformis. Two types of cercariae were detected from the snail, N. histrio: Microphalliae and Haematoloechus similis. The mean prevalence of larval trematode infections was $21.45 \%$. The most prevalent infected snail species was $N$. histrio (31.94\%) followed by N. albicilla $(24.34 \%)$ and $N$. orbignyana $(23.08 \%)$. The prevalence of infection in the species $N$. grayana was $21.98 \%$ and N. quadricolor $16.13 \%$, while $N$. polita snails had the lowest infection prevalence of $3.77 \%$ (Table 1 ). 
Table 1: The overall infection prevalence in different snail species collected from north Obhor

\begin{tabular}{|c|c|c|}
\hline Infection percent & Type of cercaria & Snail species \\
\hline 24.34 & $\begin{array}{l}\text { virgulate cercaria } \\
\text { maritrema lingulla } \\
\text { Litorina saxatilis } \mathrm{V}\end{array}$ & Nerita albicilla \\
\hline 21.98 & $\begin{array}{l}\text { litorina saxatilis } \mathrm{V} \\
\text { litorina saxatilis }\end{array}$ & Nerita grayana \\
\hline 3.77 & Furcocercus cercaria & Nerita polita \\
\hline 16.13 & Maritrema lingulla & Nerita quadricolor \\
\hline 23.08 & $\begin{array}{l}\text { Microphallus similis, Haematoloechus similis, Maritrema lingulla } \\
\text { Ascorhytis charadriformis }\end{array}$ & Nerita orbignyana \\
\hline $31.94^{*}$ & $\begin{array}{l}\text { Microphalliae } \\
\text { Haematoloechus similis }\end{array}$ & Nerita histrio \\
\hline
\end{tabular}

\section{Overall prevalence of cercariae:}

Nine distinguishable cercariae were collected from Nerita spp. The overall prevalence of infection for each cercarial type in all snail species was recorded. Cercaria of Haematoloechus similis (5.93\%), virgulate cercaria (33.89\%), cercaria of Microphalliae (16.95\%), cercaria of Ascorhytis charadriformis (1.69\%), cercaria of litorina saxatilis VII (7.63\%), cercaria of litorina saxatilis V (11.86\%), cercaria of Maritrema lingulla (16.95\%), cercaria of Microphallus similis (3.39\%) and furcocercous cercaria (1.69\%). The highest percentage of infection was recorded for virgulate cercaria $(33.89 \%)$, while the lowest was recorded for cercaria of Ascorhytis charadriformis and Furcocercous, 1.69\% (Table 2).

Table 2: Overall prevalence $(\%)$ of trematode cercariae in marine water snails collected from north Obhor, Jeddah $(*$ referred to most prevalent cercaria)

\begin{tabular}{|l|l|}
\hline Types of Trematode cercarie & \multicolumn{1}{|c|}{ Prevalence (\%) } \\
\hline \multicolumn{1}{|c|}{ Haematoloechus similis cerccariae } & 5.93 \\
\hline Virgulate cercariae & $33.89^{*}$ \\
\hline Microphalliae cercariae & 16.95 \\
\hline Ascorhytis charadriformis cerccariae & 1.69 \\
\hline litorina saxatilis VII Cercaria & 7.63 \\
\hline litorina saxatilis V Cercaria & 11.86 \\
\hline Maritrema lingulla Cercaria & 16.95 \\
\hline Microphallus similis Cercaria & 3.39 \\
\hline Furcocercous cerccariae & 1.69 \\
\hline
\end{tabular}

\section{Monthly changes in infection of Nerita spp:}

Monthly changes in the infection prevalence in each snail species was studied in table (3). Infection of $N$. albicilla, N. quadricolor and N. histrio were the highest in November with percentages of $86.36 \%, 77.78 \%$ and $71.42 \%$, respectively. On the other hand, in $N$. grayana the highest infection prevalence was in June (71.42\%). N. polita was infected during April and May only with infection rate of $50 \%$ for each month. The highest rate of infection in N. orbignyana was recorded in May (75\%).

\begin{tabular}{|c|c|c|c|c|c|c|}
\hline \multirow[b]{2}{*}{ N. histrio } & \multirow[b]{2}{*}{ N. orbignyana } & \multirow[b]{2}{*}{ N. quadricolor } & \multirow[b]{2}{*}{ N. polita } & \multirow[b]{2}{*}{ N. grayana } & \multirow[b]{2}{*}{ N. albicilla } & \multirow{2}{*}{$\begin{array}{l}\text { Types of snails } \\
\text { Months } \\
\text { (snail examined /Snail } \\
\text { shedding) } \%\end{array}$} \\
\hline & & & & & & \\
\hline- & 20 & - & - & 16.67 & 4.34 & January \\
\hline- & - & - & - & 42.10 & 5.56 & February \\
\hline- & - & - & - & - & - & March \\
\hline- & 12.5 & - & 50 & 33.33 & - & April \\
\hline 50 & $75 *$ & 50 & 50 & 50 & 77.78 & May \\
\hline 63.63 & - & 9.09 & - & $71.42^{*}$ & 41.67 & June \\
\hline- & - & - & - & 18.18 & - & July \\
\hline- & 33.33 & - & - & - & - & August \\
\hline- & 50 & 50 & - & 14.29 & 12.5 & September \\
\hline- & - & 14.29 & - & 12.5 & 16.67 & October \\
\hline $73.68 *$ & 25 & $77.78^{*}$ & - & 42.86 & $86.36^{*}$ & November \\
\hline 12.5 & 33.33 & - & - & 25 & 24.13 & December \\
\hline
\end{tabular}


Seasonal changes in the infection prevalence:

As shown in Table (4) and Figure (3), the results showed significantly different prevalence of infection percentages, with no correlation between seasonal prevalence and mean temperature. The highest prevalence of cercarial infection in snails was recorded during autumn (September, October and November) with 38\% prevalence, whilst it was lowest during winter (December, January and February) with $9.67 \%$ prevalence. Mean temperature was highest in summer $\left(29^{\circ} \mathrm{C}\right)$ and lowest in winter $\left(23^{\circ} \mathrm{C}\right)$. In autumn, the mean temperature was $\left(28^{\circ} \mathrm{C}\right)$ and in spring $\left(25^{\circ} \mathrm{C}\right)$.



Fig. 3: Seasonal changes in temperature and infection percent in Nerita snailas

\section{Correlation between snail's length and infection prevalence:}

As shown in Table (5), there is a positive correlation between infection prevalence and snail's length. The infection of the snail species, $N$. albicilla with the length of 12-14 mm was the highest (78.26\%). The length 10$11.9 \mathrm{~mm}$ had the highest infection prevalence $(71.42 \%)$ in $N$. grayana snails. In the snail species $N$. polita, infection was found only in the length $8-9.9 \mathrm{~mm}(22.22 \%)$. In N.quadricolor snails, the infection percentage was the highest in the length $8-9.9 \mathrm{~mm}(37.5 \%)$. As for $N$. orbignyana the highest percentage of infection was recorded in the snail length $10-11.9 \mathrm{~mm}(50 \%)$. The percentage of infection in $N$. histrio with length 10-11.9 $\mathrm{mm}$ was the highest (80\%). The lowest rate of infection was recorded from snails of length $2-3.9 \mathrm{~mm}$.

Table 4: Seasonal prevalence of trematode larval infection in some marine snails (* referred to highest infection percent)

\begin{tabular}{|l|l|l|}
\hline Season & Total collected & \multicolumn{1}{c|}{$(\%)$} \\
\hline & 113 & 18.58 \\
\hline Summer & 150 & $38^{*}$ \\
\hline Sinter & 207 & 9.67 \\
\hline
\end{tabular}

Table 5: The infection prevalence in relation to Nerita snails length (* referred to highest infection percent

\begin{tabular}{|c|c|c|c|c|c|c|c|}
\hline \multicolumn{6}{|c|}{$\begin{array}{l}\text { Size of snails/ infected } \\
(\%)\end{array}$} & \multirow{2}{*}{$\begin{array}{l}\text { Number of } \\
\text { examined } \\
\text { snails }\end{array}$} & \multirow[t]{2}{*}{ Snail species } \\
\hline $12-14 \mathrm{~mm}$ & $10-11.9 \mathrm{~mm}$ & $8-9.9 \mathrm{~mm}$ & $6-7.9 \mathrm{~mm}$ & $4-5.9 \mathrm{~mm}$ & $2-3.9 \mathrm{~mm}$ & & \\
\hline $78.26^{*}$ & 42.42 & 27.78 & 10 & 13.33 & 7.35 & 207 & Nerita albicilla \\
\hline 40 & $71.42 *$ & 20 & 12.5 & 21.73 & 2.86 & 101 & Nerita grayana \\
\hline - & - & $22.22^{*}$ & - & - & - & 63 & Nerita polita \\
\hline 20 & - & $37.5^{*}$ & 33.33 & 13.04 & 1.67 & 112 & Nerita quadricolor \\
\hline 25 & $* 50$ & 14.29 & 40 & 33.33 & 8 & 62 & Nerita orbignyana \\
\hline 36.84 & $80 *$ & 50 & 40 & 33.33 & 18.18 & 62 & Nerita histrio \\
\hline
\end{tabular}

\section{Discussion:}

One of the most important factors that influence the occurrence of trematode infection in marine water is the availability of suitable snail host. Snails play a very important role in the transmission of trematode species as they act as intermediate hosts in which three larval stages of the trematodes life cycle are completed 
(Sprocysts, rediae and cercariae). Several snail species of marine snails were found in the Red Sea that act as intermediate hosts for different trematodes that affect our life stock and birds.

In the present study, cercariae of nine species of digenetic trematodes belonging to six morphotypes were collected from marine Nerita snails. Total prevalence of larval trematodes in all Nerita species was $21.45 \%$. The most prevalent infected snail species was $N$. histrio $(31.94 \%)$ while, $N$. polita snails had the lowest infection prevalence $(3.77 \%)$. Few studies concerned with the prevalence in marine snails' cercarial infection such as Byers et al. (2008). On the other hand, many studies interested in the study of infection rate of fresh water snails were done all over the world such as, Hasanat et al. (2017) who recorded infection rate of $11.07 \%$ for Lymnaea snails in Pakistan. Jayawardena et al. (2011) also found 16\% infection rate for the snails, Thiara scabra, T. tuberculate, Paludomous sherica and Gyrulus saigonensis in Srilanka. In addition, Ahmed et al. (2006) recorded $14.9 \%$ infection rate in the snail, Bulinus truncates in Sudan. Differences in the overall prevalence of trematode infections may involve many factors, including different collection time, locality, season, type and number of parasite and intermediate host, availability of infected definitive or reservoir hosts. The prevalence of snails in different locations of the country was different. This was due to difference in the environmental and managemental conditions (Kulsantiwong et al. 2015 \& Pfukenyi et al. 2005). The most prevalent month of cercarial infection in Iran is May to September (Sharif et al. 2010).

Seasonality that is mirrored by changes in environmental variables can intervene in snail's ecology and influence the larval development of a trematode inside its host snail. It may also affect cercarial shedding (the release of cercariae from the host snail in nature). However, the influence of environmental elements on cercarial shedding is trematode-specific (Abrous et al. 1999).

In the present study, the highest cercarial infection rates in snails were observed during autumn (38\%), while it was lowest during winter. Infection rate of snails in different seasons are fluctuated. Hasanat et al. (2017) recorded seasonal data with high prevalence rate during autumn (19.6\%) and low in spring (4.2\%). Aboelhadid (2004) detected that, the prevalence of Schistosoma mansoni cercariae was high in spring (8.3\%) and Imani-Baran et al. (2011) found high infection rate in early summer (June- July) in Iran. Seasonal data of Tanveer \& Khan (1989), Maqbool et al. (1998), Khan et al. (2008) showed significantly higher number of snails in summer. Almost all snails' genera had highest prevalence in summer season. Different results for seasonally infection rate might be due to low levels of water, slow-flowing in the stream during hot non-rainy season, also it could be due to high contamination by the faecal matter of livestock, birds and other animals. It is probably that snail abundance is low in the summer and miracidia enter most available snails. Thus, it can be anticipated that, both snail's propagation and their infection with trematodes are correlated with seasonal variations. various ecological factors such as season and water temperature, $\mathrm{pH}$ and dissolved oxygen influence the emergence of cercariae from the snails and their release inside the water resources. snails can reach their maximum incidence during summer and autumn providing optimum temperature required for their breeding and reproduction (Farahnak et al. 2011).

Environmental conditions in different habitats, in different climatic zones may support the trematode life cycle differently. Trematodes show distinct and direct relationship with the temperature in their transmission process. Cercarial output is directly influenced by the temperature due to both stimulating effect of temperature increasing the emergence from the snail and the acceleration of cercarial production within the snail host. However, under high temperature conditions some cercariae encyst within snails. Even though, snail populations grant higher trematode diversity (Smyth 1962, Poulin 2006). The cercarial shedding is related to temperature, humidity and rainfall; temperature between $25-30{ }^{\circ} \mathrm{C}$ is favorable for shedding of cercariae (Alim 1997, Rahman et al. 1997). These conditions favor the growth and development of vector snails and hasten the development and shedding of cercariae from snails by rapid development of miracidium to sporocyst, redia and finally cercariae (Alim 1997).

Transmission of digenetic trematodes from the snail to the next host in the life cycle depends largely on the proportion of snails that release cercariae, as well as the number of cercariae released from each infected snail (Anderson \& May 1991). These factors may be quantified, respectively, in terms of the prevalence and intensity of patent infection (Margolis et al. 1982, Bush et al.1997). In field populations, both these factors tend to increase with increasing snail size. In the present study, infection prevalence of Nerita spp is positively related to their length. Among freshwater snails, for example, a positive correlation between snail size and the prevalence of infection was reported in $73 \%$ of the field studies reviewed by Sorensen \& Minchella (2001). Size may also be positively correlated with intensity of infection (Smith, 1984). For both mammalian and avian schistosomes, the prevalence and intensity of infection tend to be highest among the largest snails (Sturrock 1973, Kulesa et al. 1982, Loker 1983, Woolhouse 1989, Niemann \& Lewis 1990). Large snails are older, on average, than small snails, within a given population (Minchella et al. 1985). This age variation translates into differential exposure to and duration of infection among snails of differing sizes because larger-older snails may have been exposed to more miracidia or may have been infected for a longer period and thus have patent, highly productive infections. A complete coupling between age and size would require further experimental work. Trematode induced gigantism can disrupt the correlation between age and size of snails by accelerating the 
growth of infected snails. Thus, infected snails would always be in the largest size classes. On the other hand, most authors who have reported such gigantism found that the growth acceleration is overcome on the time scale of these experiments. They concluded that gigantism does not underline the increases in prevalence and intensity with increasing size in this field system (McClelland \& Bourns 1969, Loker 1979, Minchella et al. 1985, Joosse \& van Elk, 1983).

\section{Conclusion And Recommendations:}

We have concluded that there is a positive correlation between infection percent and snail's length. The highest infection prevalence was recorded in autumn. Studying both the infection prevalence of larval trematodes as well as the most prevalent infected snail length in marine snails are of great importance. These trematodes can be transmitted to the surrounding fish, birds and other vertebrates in marine habitat. Such studies can assist in collecting data on the ecological relevance of disease distribution in the sympatric fish and the pattern of transmission of digenean trematodes by snails and finally, in prevention and control of the following fish and human diseases.

\section{REFERENCES}

Aboelhadid, S.M., 2004. Biological studies on parasites transmitted from some freshwater snails to other hosts (Doctoral dissertation, Ph. D. Thesis, Faculty of Veterinary Medicine, Beni-Suef, Cairo University).

Aboelhadid, S.M., M. Thabet, D. El-Basel and R. Taha, 2016. Digenetic larvae in Schistosome snails from El Fayoum, Egypt with detection of Schistosoma mansoni in the snail by PCR. Journal of Parasitic Diseases, 40(3): 730-734. doi: 10.1007/s12639-014-0567-7.

Abrous, M., D. Rondelaud and G. Dreyfuss, 1999. Paramphistomum daubneyi and Fasciola hepatica: influence of temperature changes on the shedding of cercariae from dually infected Lymnaea truncatula. Parasitology research, 85(8): 765-769.

Ahmed, A.A.M., N.A. Ibrahim and M.A. Idris, 2006. Laboratory studies on the prevalence and cercarial rhythms of trematodes from Bulinus truncatus and Biomphalaria pfeifferi snails from Khartoum state, Sudan. Sultan Qaboos University Medical Journal, 6(2): 65.

Alim, M.A., 1997. Some epidemio-pathological aspects of fascioliasis in buffaloes in Bangladesh. Department of Parasitology, Bangladesh Agricultural University, Mymensingh.

Anderson, R.M. and R.M. May, 1991. Infectious diseases of humans:Dynamics and control. Oxford University Press, Oxford, U.K., p: 757.

Arshad, G.M., A. Maqbool, M.F. Qamar, S.M.H. Bukhari, H.A. Hashmi and M. Ashraf, 2011. Prevalence and ecology of fresh water snails in some selected districts of southern Punjab, Pakistan. Pakistan Journal of life and social Science, 9: 17-20.

Bdir, S. and G. Adwan, 2011. Larval stages of digenetic trematodes in Melanopsis praemorsa snails from freshwater bodies in Palestine. Asian Pacific journal of tropical biomedicine, 1(3): 200-204. doi: 10.1016/S2221-1691(11)60027-0

Bush, A.O., K.D. Lafferty, J.M. Lotz and A.W. Shostak, 1997. Parasitology meets ecology on its own terms: Margolis et al. revisited. The Journal of parasitology, pp: 575-583.

Byers, J.E., A.M. Blakeslee, E. Linder, A.B. Cooper and T.J. Maguire, 2008. Controls of spatial variation in the prevalence of trematode parasites infecting a marine snail. Ecology, 89(2): 439-451.

Farahnak, A., R. Vafaie-Darian and I. Mobedi, 2006. A Faunistic Survey of Cercariae from Fresh Water Snails: Melanopsis spp. and their Role in Transmission Diseases. Iranian Journal of Public Health, 35(4): $70-74$.

Graczyk, T.K. and B.E. Fried, 1999. Development of Fasciola hepatica in the intermediate host. Fasciolosis. Dalton JP, Editor. CABI Publishing: Oxon, pp: 31-46.

Hasanat, A., N. Sia, M.I. Shahzad, S.B. Rasheed and Z. Hasan, 2017. Prevalence of Fasciola Cercariae in Snail (Intermediate host) and its Correlation with Various Meteorological Factors in Bahawalpur, Pakistan. Sudan Journal of Vet. Res., 32: 11-15.

Imani-Baran, A., M. Yakhchali, R. Malekzadeh Viayeh and F. Farhangpajuh, 2011. Prevalence of Cercariae Infection in Lymnaea auricularia (Linnaeus, 1758) in North West of Iran. In Veterinary Research Forum. Faculty of Veterinary Medicine, Urmia University, 2(2): 121-127.

Islam, Z., M.Z. Alam, S. Akter, B.C. Roy and M.M.H. Mondal, 2013. Distribution patterns of vector snails and trematode cercaria in their vectors in some selected areas of Mymensingh. Journal of Environmental Science and Natural Resources, 5(2): 37-46. dx.doi.org/10.3329/jesnr.v5i2.14599.

Jamjoom, M.B. and A.A. Banaja, 2007. Comparative studies on the susceptible and non-susceptible Biomphalaria alexandrina in the intermediate snail host of Schistosoma mansoni in Western Saudi Arabia. World Journal of Medical Sciences, 2(2): 108-114. 
Jayawardena, U., R. Rajakaruna and P. Amerasinghe, 2011. Cercariae of trematodes in freshwater snails in three climatic zones in Sri Lanka. Ceylon Journal of Science (Biological Sciences), 39(2). doi.org/10.4038/cjsbs.v39i2.2996.

Joosse, J. and R. van Elk, 1983. Intervention of a trematode parasite in the action of the female gonadotrophic hormones on the albumen gland of Lymnaea stagnalis.[In:] Molluscan Neuro-endocrinology (Edited by J. Lever and HH Boer).

Khan, U.J., A. Tanveer, A. Maqbool and S. Masood, 2008. Epidemiological studies of paramphistomosis in cattle. Veterinarski Arhiv, 78(3): 243.

Knaap, W.V.D. and E.S. Loker, 1990. Immune mechanism in Trematode-snail interaction. Parasitology today, 6(6): 175-182.

Koprivnikar, J. and R. Poulin, 2009. Effects of temperature, salinity, and water level on the emergence of marine cercariae. Parasitology research, 105(4): 957.

Kulesa, M.W., H.D. Blankespoor and K.E. Roney, 1982. Prevalence of avian schistosomes in Physa integra from southwestern Michigan. In Proc. Helminthol. Soc. Wash, 49(1): 14-18.

Kulsantiwong, J., S. Prasopdee, S. Piratae, P. Khampoosa, C. Thammasiri, A. Suwannatrai and S. Tesana, 2015. Trematode Infection of Freshwater Snail, Family Bithyniidae in Thailand. Southeast Asian Journal of Tropical Medicine and Public Health, 46(3): 396.

Loker, E.S., 1979. Effects of Schistosomatium douthitti infection on the growth, survival, and reproduction of Lymnaea catascopium. Journal of Invertebrate Pathology, 34(2): 138-144.

Loker, E.S., 1983. A comparative study of the life-histories of mammalian schistosomes. Parasitology, 87(2): 343-369.

Maqbool, A., C.H. Hayat, T. Akhtar, A.D. Anjum and B. Hayat, 1998. Prevalence and ecology of fresh water snails in Punjab. Malaysian applied Biology, 27: 69-72.

Margolis, L., G.W. Esch, J.C. Holmes, A.M. Kuris and G. Schad, 1982. The use of ecological terms in parasitology (report of an ad hoc committee of the American Society of Parasitologists). The Journal of Parasitology, 68(1): 131-133.

McClelland, G. and T.K.R. Bourns, 1969. Effects of Trichobilharzia ocellata on growth, reproduction, and survival of Lymnaea stagnalis. Experimental Parasitology, 24(2): 137-146.

Minchella, D.J., B.K. Leathers, K.M. Brown and J.N. McNair, 1985. Host and parasite counteradaptations: an example from a freshwater snail. The american naturalist, 126(6): 843-854.

Niemann, G.M. and F.A. Lewis, 1990. Schistosoma mansoni: influence of Biomphalaria glabrata size on susceptibility to infection and resultant cercarial production. Experimental parasitology, 70(3): 286-292.

Pfukenyi, D.M., S. Mukaratirwa, A.L. Willingham and J. Monrad, 2005. Epidemiological studies of amphistome infections in cattle in the highveld and lowveld communal grazing areas of Zimbabwe. Onderstepoort Journal of Veterinary Research, 72(1): 67-86. doi: 10.4102/ojvr.v72i1.224.

Poulin, R., 2006. Global warming and temperature-mediated increases in cercarial emergence in trematode parasites. Parasitology, 132(1): 143-151. doi.org/10.1017/S0031182005008693.

Rahman, M.H., N. Begum and A. Alim, 1997. Factors for the development of Furcocercus and other cercariae in snails and their release. The Bangladesh Veterinaria, 14: 29.

Rusmore-Villaume, M.L., 2008. Seashells of the Egyptian Red Sea: The Illustrated Handbook. American University in Cairo Press.

Sharif, M., A. Daryani and S.A. Karimi, 2010. A Faunistic Survey of Cercariae Isolated from Lymnaeid Snails in Central Areas of Mazandaran. Pakistan Journal of Biological Sciences, 13(4): 158-163. doi: 10.3923/pjbs.2010.158.163.

Smith, G., 1984. The relationship between the size of Lymnaea truncatula naturally infected with Fasciola hepatica and the intensity and maturity of the redial infection. Journal of helminthology, 58(2): 123-127.

Smyth, J.D., 1962. Introduction to Animal Parasitology, Cambridge University Press. pp: 196-198.

Sorensen, R.E. and D.J. Minchella, 2001. Snail-trematode life history interactions: past trends and future directions. Parasitology, 123(7): S3-S18.

Sturrock, R.F., 1973. Field studies on the transmission of Schistosoma mansoni and on the bionomics of its intermediate host, Biomphalaria glabrata, on St. Lucia, West Indies. International journal for parasitology, 3(2): 175-194.

Tanveer, A. and D. Khan, 1989. Seasonal variations in the environmental factors and snail populations in four different habitats around Lahore. Punjab University Journal of Zoology, 4: 31-69.

Woolhouse, M.E.J., 1989. On the interpretation of age-prevalence curves for schistosome infections of host snails. Parasitology, 99(1): 47-56.

Żbikowska, E. and A. Nowak, 2009. One hundred years of research on the natural infection of freshwater snails by trematode larvae in Europe. Parasitology research, 105(2): 301. 